\title{
Hypoalaninemia: a Concomitant of Ketotic Hypoglycemia
}

\author{
Anthony S. Pagliara, Irene E. Karl, Darryl C. De Vivo, \\ Ralph D. Feigin, and David M. KipNis \\ From the Department of Medicine and the Edward Mallinckrodt Department \\ of Pediatrics, Washington University School of Medicine, \\ St. Louis, Missouri 63110
}

A B S T R A C T The cause of of ketotic hypoglycemia, the commonest form of hypoglycemia in childhood, is not known. The present study was undertaken to determine whether the primary defect in this condition is a deficiency of gluconeogenic precursor(s) or an abnormality in the hepatic gluconeogenic enzyme system. Plasma glucose, alanine, and insulin and blood $\beta$-hydroxybutyrate $(\beta-\mathrm{OHB})$, pyruvate, and lactate levels were determined in eight ketotic hypoglycemic children and seven agematched controls maintained on a normal diet and after being fed a provocative hypocaloric low-carbohydrate diet $\left(1200 \mathrm{kcal} / 1.73 \mathrm{~m}^{2}, 15 \%\right.$ carbohydrate, $17 \%$ protein, and $68 \%$ fat). On a normal diet, overnight fasting plasma alanine $\left(211 \pm 10 \mu_{M}\right)$ and glucose $(68 \pm 4 \mathrm{mg} / 100$ $\mathrm{ml})$ were significantly lower and blood $\beta$-OHB (1.22 \pm $0.37 \mathrm{~mm}$ ) significantly higher in ketotic hypoglycemic children than in controls (alanine, $315 \pm 15 \mu \mathrm{M}$; glucose, $81 \pm 3 \mathrm{mg} / 100 \mathrm{ml} ; \beta-\mathrm{OHB}, 0.18 \pm 0.08 \mathrm{~mm}$ ).

All ketotic hypoglycemic children developed symptomatic hypoglycemia $(33 \pm 3 \mathrm{mg} / 100 \mathrm{ml})$ and ketosis $(\beta-\mathrm{OHB}, 3.70 \pm 0.32 \mathrm{~mm})$ 8-16 hr after starting the provocative diet and these changes were associated with a further decline in plasma alanine $\left(155 \pm 17 \mu_{\mathrm{M}}\right)$. Normal children, even after $36 \mathrm{hr}$ on this diet, maintained higher plasma glucose $(48 \pm 2 \mathrm{mg} / 100 \mathrm{ml})$ and alanine $\left(225 \pm 5 \mu_{\mathrm{M}}\right)$ and lower $\beta$-OHB levels $(2.56 \pm 0.44 \mathrm{~mm})$.

Intravenous infusions of alanine $(250 \mathrm{mg} / \mathrm{kg}) \mathrm{uni}$ formly restored the hypoglycemic plasma glucose levels

This work was presented in part at the meeting of the American Society for Clinical Investigation, Atlantic City, N. J., May 1971. (1971. J. Clin. Invest. 50: 73a). (Abstr.)

Dr. Pagliara performed this work during tenure as a Daland Fellow of the American Philosophical Society and under U. S. Public Health Service Training Grant Number 5-T1-AM-5027-14. Dr. Feigin is the recipient of a U. S. Public Health Service Career Development Award No. 1K04AI46206 from the National Institute of Allergy and Infectious Diseases.

Received for publication 18 October 1971 and in revised form 15 December 1971. of ketotic hypoglycemic children to normal. Cortisone acetate $\left(300 \mathrm{mg} / \mathrm{m}^{2}\right)$, given orally in three divided doses during feeding of the provocative diet, produced a 3- to 4-fold increase in plasma alanine within 4-6 $\mathrm{hr}$ after beginning steroid therapy and completely prevented the development of hypoglycemia and ketosis. Quantitative amino acid profiles were performed and demonstrated that alanine was the only gluconeogenic amino acid which differed significantly between the two groups. Plasma insulin and blood lactate and pyruvate levels did not differ significantly between normal and ketotic hypoglycemic children under all conditions examined.

These results support the hypothesis that a deficiency in gluconeogenic precursor (e.g., alanine) rather than a defect in the hepatic gluconeogenic enzyme apparatus represents the most likely factor in the pathogenesis of ketotic hypoglycemia.

\section{INTRODUCTION}

Ketotic hypoglycemia is the most common form of hypoglycemia in young children, usually appears between the first and third years of life, and remits spontaneously by age $6-8(1,2)$. The hallmark of this clinical disorder is the appearance of recurrent episodes of hypoglycemia and ketosis which can be uniformly provoked by a brief fast after feeding a hypocaloric high fat, low carbohydrate diet (2). The pathogenesis of this disorder has not been defined although a number of etiologic possibilities have been excluded: $(a)$ serum insulin levels have been reported to be appropriate for the blood glucose level $(3,4),(b)$ infusions of glycerol (3) and fructose (2) have produced prompt increases in blood glucose indicating an intact hepatic gluconeogenic system above the level of the triose phosphates, $(c)$ plasma glycerol concentrations are similar in children with ketotic hypoglycemia and normal controls both in the fed and fasted states, indicating that glycerol availability is not rate-limiting ( 3 ), and $(d)$ infusions of $\beta$-hydroxy- 
TABLE I

Clinical Data on Eight Patients with Ketotic Hypoglycemia*

\begin{tabular}{|c|c|c|c|c|c|c|}
\hline Patient & Age & Sex & Height & Weight & $\begin{array}{l}\text { Lowest } \\
\text { sponta- } \\
\text { neous } \\
\text { blood } \\
\text { glucose }\end{array}$ & Comments \\
\hline & months & & inches & pounds & $m g / 100 m l$ & \\
\hline D. P. & 53 & $\mathbf{M}$ & 40 & 35 & 24 & $\begin{array}{l}\text { Moderate mental retardation. Presented with } \\
\text { seizures and coma. Normal EEG. Weak } \\
\text { spells, lethargy and irritability. }\end{array}$ \\
\hline D. C. & 42 & $\mathbf{M}$ & 37 & 33 & 34 & No seizures. Normal EEG. \\
\hline B. I. & 48 & $\mathbf{M}$ & 38 & 33 & 8 & Grand mal seizure. Normal EEG. \\
\hline A. V. & 56 & $\mathrm{~F}$ & 44 & 37 & 8 & $\begin{array}{l}\text { Seizures and coma on several occasions. On } \\
\text { dilantin. Normal EEG. }\end{array}$ \\
\hline R. G. & 30 & $\mathrm{~F}$ & 35 & 24 & 18 & Grand mal seizure. Normal EEG. \\
\hline J. F. & 39 & $\mathrm{~F}$ & 35 & 33 & 39 & $\begin{array}{l}\text { Mixed seizure disorder. EEG abnormal. On } \\
\text { tridione and mysoline. }\end{array}$ \\
\hline M. W. & 36 & $\mathbf{M}$ & 34 & 30 & 27 & Presented with grand mal seizure. Normal EEC \\
\hline B. F. & 30 & $\mathbf{M}$ & 34 & 26 & 17 & Generalized seizures. EEG normal. \\
\hline
\end{tabular}

* All patients exhibited a "strong" nitroprusside urinary ketone reaction at the time of hypoglycemia. Liver function tests (i.e., serum glutamic-oxaloacetic acid transaminase, serum glutamic-pyruvic transaminase, alkaline phosphatase, bilirubin, and serum proteins) were normal in all subjects.

butyrate $(\beta-\mathrm{OHB})^{1}$ have not elicited any responses which differ from those seen in normal children (5).

In light of these studies, the characteristic inability of children with ketotic hypoglycemia to respond to glucagon after brief caloric restriction (2) suggested to us the existence of either a hepatic enzymatic abnormality below the level of the triose phosphates in the gluconeogenic sequence or a deficient supply of gluconeogenic precursor $(s)$. Both of these possibilities have been explored in the present study. Plasma alanine concentrations as well as quantitative amino acid profiles and blood lactate and pyruvate levels were measured as an index of the availability of gluconeogenic precursors in normal and ketotic hypoglycemic children before and during caloric restriction. In addition, the glycemic response to alanine in the face of symptomatic hypoglycemia was determined to evaluate the complete integrity of the hepatic gluconeogenic pathway.

\section{METHODS}

Eight children with ketotic hypoglycemia (Table I) and seven age-matched controls were admitted to the Washington University Clinical Research Center in St. Louis Children's Hospital. All patients were between the 10th and 18th percentile for height and weight. The presumptive diagnosis of ketotic hypoglycemia was made in all subjects, except for J. F., on the basis of previous clinical and laboratory observations. The subjects were placed on a standard hospital diet (45\% carbohydrate, $35 \%$ fat, $20 \%$ protein) for at least $48 \mathrm{hr}$ before study. Venous blood samples were obtained from an indwelling needle in the

${ }^{1}$ Abbreviations used in this paper: K-H, ketotic hypoglycemic ; $\beta$-OHB, $\beta$-hydroxybutyrate. brachial vein. $1 \mathrm{ml}$ samples of blood were deproteinized immediately with $1 \mathrm{ml}$ of ice-cold $3 \mathrm{M}$ perchloric acid for determination of $\beta$-OHB (6), lactate, and pyruvate (7). Other blood samples were heparinized and the plasma separated and stored at $-20^{\circ} \mathrm{C}$ until analyzed for glucose (8), alanine by fluorometric enzymatic assay, ${ }^{2}$ amino acids by quantitative column chromatography (9), and insulin by radioimmunoassay $(10)$. The study protocol involved the following sequence: $(a)$ on the $3 \mathrm{rd}$ or 4th hospital day, base line blood samples (hereafter referred to as postabsorptive levels) were drawn at 8:00 a.m. (12-15 hr postprandial) and glucagon $(0.03 \mathrm{mg} / \mathrm{kg}$ body weight $)$ was injected intravenously to assess the glycemic response of the patient while maintained on a normal hospital diet; $(b)$ the following day, base line blood samples were obtained at 8:00 a.m. and the subjects were then started on a provocative hypocaloric diet consumed in equal portions at 8:00 a.m., noon, and 5:00 p.m. This diet contained 1200 kcal per $1.73 \mathrm{~m}^{2}$ body surface area, with the following caloric distribution: $68 \%$ fat, $17 \%$ protein, and $15 \%$ carbohydrate (2). After the 5:00 p.m. feeding, food was withheld for an additional $24-27 \mathrm{hr}$ in the normal subjects and until symptomatic hypoglycemia appeared in the ketotic hypoglycemic patients. Immediately before refeeding, the glycemic response to intravenous glucagon was again assessed. In seven subjects with ketotic hypoglycemia, the provocative ketogenic diet was repeated and alanine administered intravenously $(250 \mathrm{mg} / \mathrm{kg})$ or orally $(500 \mathrm{mg} /$ $\mathrm{kg})$ as soon as symptomatic hypoglycemia appeared. In one subject, a third provocation was performed and $40 \mathrm{mg}$ cortisone acetate was given orally every $6 \mathrm{hr}$ for three doses during the ketogenic diet.

L-Alanine (Sigma Chemical Co., St. Louis, Mo.) was prepared for intravenous infusion as a $10 \%$ solution in

${ }^{2}$ Karl, I. E., A. S. Pagliara, and D. M. Kipnis. A specific enzymatic fluorometric assay for the determination of the amino acid alanine. Manuscript in preparation. 
TABLE II

Plasma Glucose and Alanine and Blood $\beta-O H B$, Lactate, and Pyruvate Levels in Normal and Hypoglycemic Children before and after Ketotic Provocation

\begin{tabular}{|c|c|c|c|c|c|}
\hline Experimental conditions & Glucose & $\begin{array}{l}\beta \text {-Hydroxy- } \\
\text { butyrate }\end{array}$ & Alanine & Lactate & Pyruvate \\
\hline Normal hospital diet & $m g / 100 m l$ & $m \mathbf{M}$ & $\mu \mathrm{M}$ & $m \mathrm{M}$ & $m \mathrm{M}$ \\
\hline Normal (7) & $81 \pm 3.0^{*}$ & $0.18 \pm 0.08$ & $315 \pm 15$ & $1.42 \pm 0.26$ & $0.074 \pm 0.017$ \\
\hline Ketotic hypoglycemia (8) & $68 \pm 4.0$ & $1.22 \pm 0.37$ & $211 \pm 10$ & $1.24 \pm 0.17$ & $0.086 \pm 0.012$ \\
\hline$P$ & $<0.05$ & $<0.05$ & $<0.01$ & NS & NS \\
\hline \multicolumn{6}{|c|}{ Hypocaloric low carbohydrate diet } \\
\hline $\begin{array}{l}\text { Normal (7) } \\
32-36 \text { hr } \ddagger\end{array}$ & $48 \pm 2.0$ & $2.56 \pm 0.44$ & $225 \pm 5$ & $1.37 \pm 0.13$ & $0.080 \pm 0.017$ \\
\hline $\begin{array}{l}\text { Ketotic hypoglycemia (8) } \\
8-16 \text { hrt }\end{array}$ & $33 \pm 3.0$ & $3.70 \pm 0.32$ & $155 \pm 17$ & $1.23 \pm 0.15$ & $0.090 \pm 0.019$ \\
\hline$P$ & $<0.01$ & $<0.05$ & $<0.02$ & NS & NS \\
\hline
\end{tabular}

* All values represent mean \pm SEM.

$\ddagger$ Period beginning with feeding of hypocaloric diet.

sterile pyrogen-free water, passed through a $0.45 \mu$ Millipore filter (Millipore Corporation, Bedford, Mass.), and autoclaved. No adverse effects were noted upon administration in any of the patients.

\section{RESULTS}

Blood and plasma metabolite levels in normal and ketotic hypoglycemic children before and after a provocative ketogenic diet (Table II). Postabsorptive plasma alanine levels of ketotic hypoglycemic children (211士 $10 \mu_{\mathrm{M}}$, all values represent mean \pm SEM) maintained on a standard hospital diet were significantly lower $(P<$ $0.01)$ than those of the control group $\left(315 \pm 15 \mu_{\mathrm{M}}\right)$. Correspondingly, plasma glucose levels of ketotic hypoglycemic children were also significantly reduced $(P<$ $0.05)$ and blood $\beta$-OHB concentrations significantly increased $(1.22 \pm 0.37 \mathrm{~mm}$ vs. $0.18 \pm 0.08 \mathrm{~mm}, P<0.05)$. When these children were started on the provocative ketogenic diet regimen, they all rapidly developed symptomatic hypoglycemia. Within 8-16 hr after beginning the provocative diet, their plasma glucose $(33 \pm 3 \mathrm{mg} /$ $100 \mathrm{ml}$ ) and plasma alanine $\left(155 \pm 17 \mu_{\mathrm{M}}\right)$ fell to very low levels and their blood $\beta$-OHB increased markedly $(3.70 \pm 0.32 \mathrm{~mm})$. In contrast, plasma glucose levels in normal children $15 \mathrm{hr}$ after beginning the provocative diet were $60 \pm 5 \mathrm{mg} / 100 \mathrm{ml}$ (Fig. 1), and even after $32-36 \mathrm{hr}$ their plasma glucose $(48 \pm 2 \mathrm{mg} / 100 \mathrm{ml})$ and alanine $\left(225 \pm 5 \mu_{\mathrm{M}}\right)$ levels were still significantly greater than those seen in the ketotic hypoglycemic group 8-16 $\mathrm{hr}$ after initiating the provocative diet. Furthermore, none of the control children exhibited symptoms of hypoglycemia. Normal children also developed modest ketosis $(\beta-\mathrm{OHB}, 2.56 \pm 0.44 \mathrm{mM})$ consistent with the duration of the fasting. Plasma lactate and pyruvate concentra- tions were the same in both normal and ketotic hypoglycemic children under all conditions studied.

The time-course for the changes occurring in both groups after initiation of the provocative diet is shown in Fig. 1. Plasma glucose and alanine were significantly higher and blood $\beta$-OHB significantly lower in normal children throughout the time period studied.

The relationship between plasma glucose and blood $\beta$-OHB levels in ketotic hypoglycemic and normal chil-
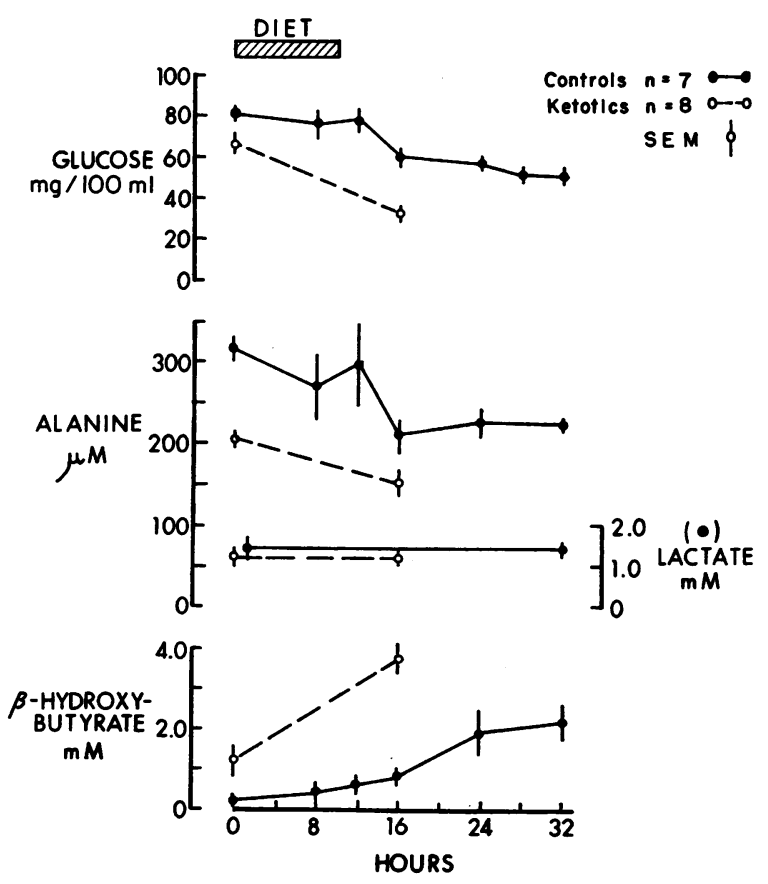

Figure 1 Substrate changes after the ketogenic diet in ketotic hypoglycemic and control children. 
dren before and during the provocative diet is shown in Fig. 2. There is a highly significant inverse linear correlation between these two blood metabolites in both groups $(r=-0.98, P<0.001$ in the ketotic hypoglycemic subjects; $r=-0.72, P<0.001$ in the control children). However, the slopes of the two regression curves do not differ significantly $(P>0.1)$, suggesting that the ketosis in ketotic hypoglycemic children is not a causative factor in the development of hypoglycemia but rather secondary to the depressed blood sugar levels in this condition.

Effect of glucagon on blood and plasma metabolite and hormone levels. Responses to intravenous glucagon before and after the provocative diet are shown in Fig. 3. Both groups exhibited similar glycemic and insulin secretory responses in the postabsorptive state. Plasma alanine levels decreased in both groups after glucagon administration, but the initial levels in ketotic hypoglycemic children are lower and fell to a greater degree than noted in normal children. In four normal children glucagon was administered $16 \mathrm{hr}$ after beginning the provocative diet. All demonstrated an increase in plasma glucose from $65 \pm 12$ to $101 \pm 28 \mathrm{mg} / 100 \mathrm{ml}$ within 30 min. This finding suggests that adequate glycogen stores are maintained for at least this period of time in normal subjects. After initiation of the provocative diet (8-16 $\mathrm{hr}$ for the ketotic hypoglycemic children and 32-36 hr for normal children), neither group had a glycemic response to glucagon, indicating depletion of hepatic glycogen stores. Plasma insulin levels were low in both groups $(<5 \mu \mathrm{U} / \mathrm{ml})$ and did not increase after intravenous glucagon administration. These data support previous studies in humans indicating that ketones are

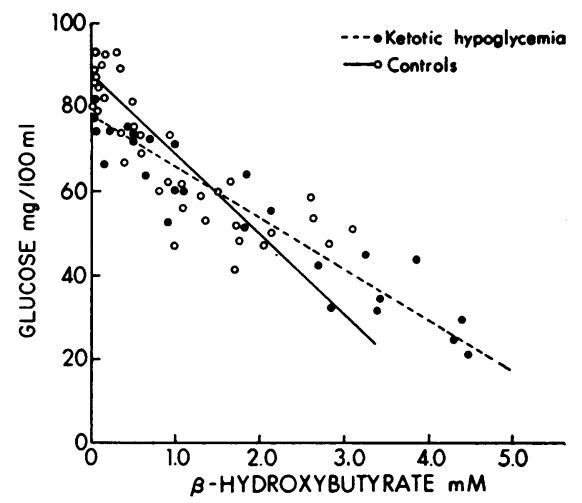

FIGURE 2 Relationship between plasma glucose and blood $\beta$-hydroxybutyrate concentrations in children with ketotic hypoglycemia and control children before and during the provocative ketogenic diet. Regression lines $y$ (glucose milligrams per $100 \mathrm{ml})=\mathrm{a}+\mathrm{b} x \quad(\beta$-hydroxybutyrate millimolar) were $y=78.5-12.5 x, r=-0.98, P<0.001(\bullet--)$ for the ketotic hypoglycemic children and $y=87.4-19.5 x$, $r=-0.72, P<0.001(\bigcirc-)$ for the controls.

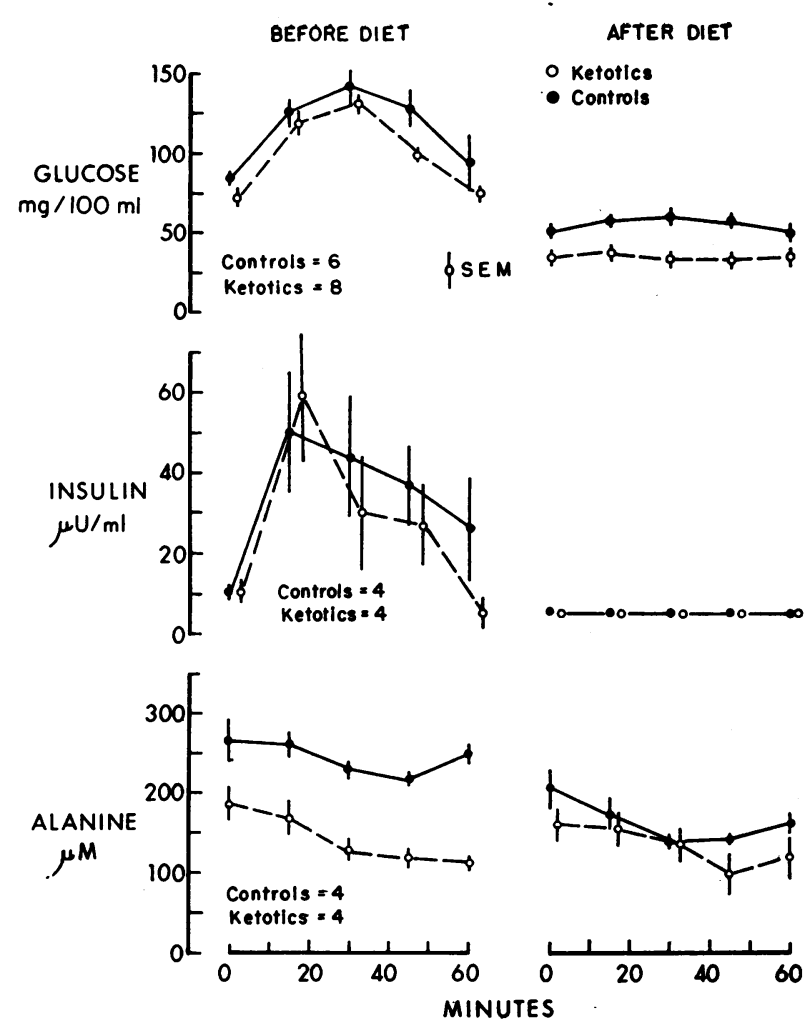

FIGURE 3 Response to intravenous injection of $0.03 \mathrm{mg} / \mathrm{kg}$ glucagon before and after the provocative ketogenic diet.

not a significant mediator of insulin secretion $(5,32)$ and also demonstrate that glucagon is not an effective insulin secretogogue in the presence of hypoglycemia.

Response to oral or intravenous alanine. The administration of alanine either orally $(500 \mathrm{mg} / \mathrm{kg})$ or intravenously $(250 \mathrm{mg} / \mathrm{kg})$ in seven subjects with ketotic hypoglycemia uniformly restored their plasma glucose to normal levels and produced a concomitant decrease in blood $\beta$-OHB. Fig. 4A illustrates a typical response to oral alanine administration. The plasma alanine level increased initially to $960 \mu_{\mathrm{M}}$ and remained at near normal levels $\left(400-500 \mu_{\mathrm{M}}\right)$ for over $90 \mathrm{~min}$. During this period, the patient's plasma glucose rose from 40 to $80 \mathrm{mg} / 100$ $\mathrm{ml}$, remained above $75 \mathrm{mg} / 100 \mathrm{ml}$ for $90 \mathrm{~min}$, and was associated with the disappearance of somnolence and ataxia and a decrease in $\beta$-OHB from 3.1 to $1.8 \mathrm{~mm}$. Of particular note is the fact that blood lactate and pyruvate levels remained constant throughout. Fig. 4B illustrates a typical response to the intravenous infusion of alanine $(250 \mathrm{mg} / \mathrm{kg}$ body weight over $30 \mathrm{~min})$. The plasma glucose increased progressively from 38 to $58 \mathrm{mg} /$ $100 \mathrm{ml}$, blood $\beta$-OHB decreased from 4.4 to $3.4 \mathrm{~mm}$, blood lactate and pyruvate levels remained constant, and the patient demonstrated considerable symptomatic improvement. 
A.
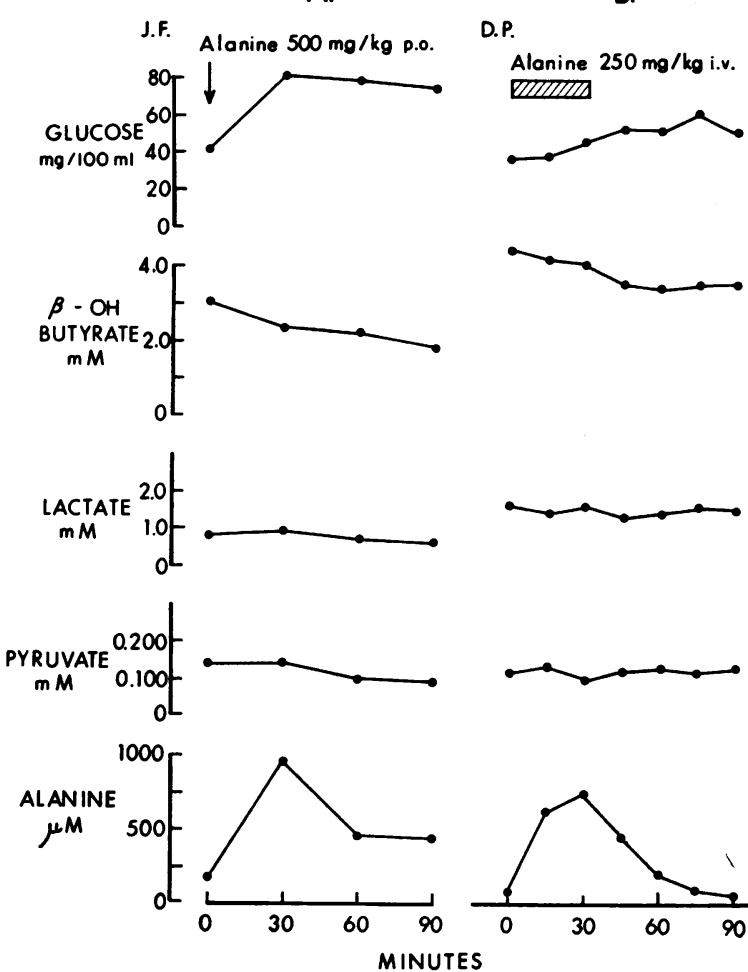

FIgURE 4 Response to alanine administration. J. F. received $500 \mathrm{mg} / \mathrm{kg}$ alanine orally (A). D. P. received 250 $\mathrm{mg} / \mathrm{kg}$ alanine intravenously over a $30 \mathrm{~min}$ period (B).

Fig. 5 illustrates the response to the intravenous administration of a bolus of alanine $(250 \mathrm{mg} / \mathrm{kg}$ body weight injected over $3 \mathrm{~min}$ ) in four patients with ketotic hypoglycemia. All subjects exhibited a progressive increase in plasma glucose $(33 \pm 5$ to $59 \pm 9 \mathrm{mg} / 100 \mathrm{ml}$, $P<0.01)$. The initial levels of plasma insulin were less

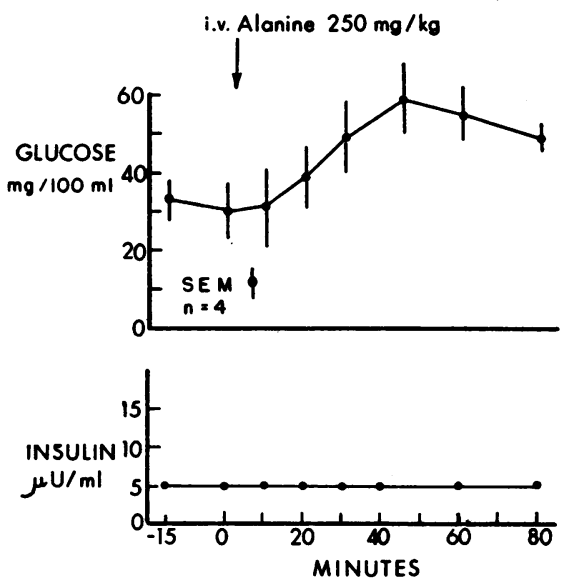

FIGURE 5 Response to intravenous bolus administration of alanine $250 \mathrm{mg} / \mathrm{kg}$ body weight in four patients with ketotic hypoglycemia. than $5 \mu \mathrm{U}$ per $\mathrm{ml}$, the lower detectable limits of the assay system, and did not rise after the administration of alanine.

Fig. 6 illustrates the response of a patient with symptomatic hypoglycemia to the sustained intravenous infusion of alanine $(33 \mathrm{mg} / \mathrm{min}$ for $140 \mathrm{~min})$. Plasma glucose increased from 30 to $60 \mathrm{mg} / 100 \mathrm{ml}$ with a fall in $\beta$-OHB from 4.0 to $2.0 \mathrm{~mm}$. At the termination of the alanine infusion, glucagon was injected intravenously $(0.03 \mathrm{mg} / \mathrm{kg}$ body weight) and elicited a prompt glycemic response (plasma glucose increased from 60 to 90 $\mathrm{mg} / 100 \mathrm{ml}$ ).

Response to cortisone acetate. It has previously been demonstrated that glucocorticoid administration prevents the development of ketosis and hypoglycemia in susceptible children given a provocative diet (2). Fig. 7 illustrates the metabolic changes occurring in a ketotic hypoglycemic child given a provocative ketogenic diet with and without cortisone acetate. On this diet, the patient rapidly became hypoglycemic, the plasma glucose level fell to $20 \mathrm{mg} / 100 \mathrm{ml}$ within $18 \mathrm{hr}$ of beginning the diet. When $40 \mathrm{mg}$ cortisone acetate was given orally every $6 \mathrm{hr}$ for three doses during the diet, plasma glucose increased and never fell below $80 \mathrm{mg} / 100 \mathrm{ml}$ even $24 \mathrm{hr}$ after initiating the provocative diet. Steroid administration also prevented the appearance of ketosis. Plasma alanine levels in this patient were consistently less than $200 \mu_{\mathrm{M}}$ before the administration of cortisone acetate. However, within $4 \mathrm{hr}$ of initiating steroid treatment, the plasma alanine level increased from 190 to $370 \mu_{\mathrm{M}}$ and remained elevated throughout the period of steroid administration. We have recently developed an

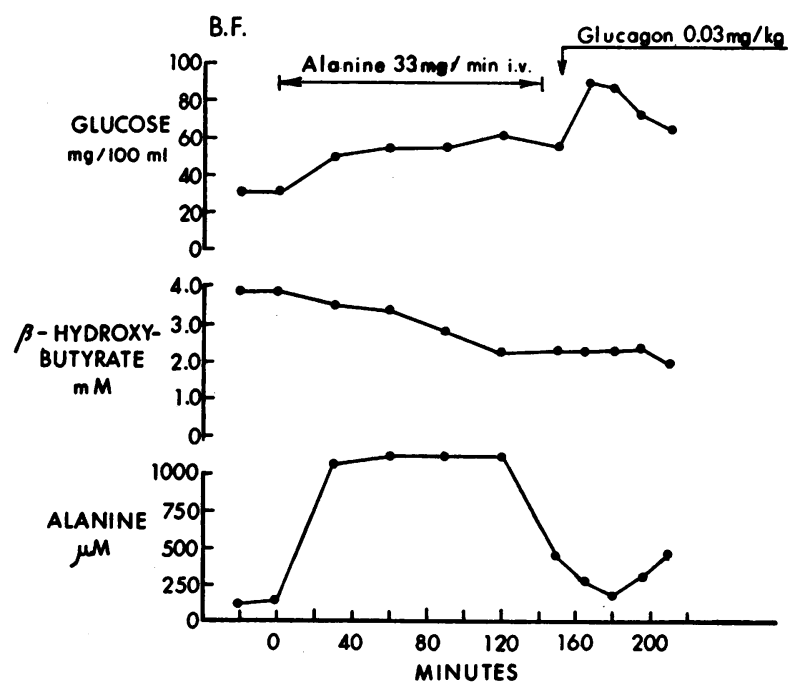

Figure 6 Response to a constant intravenous infusion of alanine (33 mg/ $\mathrm{kg}$ body weight per $\mathrm{min}$ ) for $140 \mathrm{~min}$, followed by intravenous glucagon administration $(0.03 \mathrm{mg} /$ $\mathrm{kg}$ body weight) in patient $\mathrm{B}$. F. 
enzymatic fluorometric assay for the determination of the gluconeogenic amino acid glutamine. ${ }^{3}$ Plasma glutamine paralleled the changes seen in plasma alanine. As anticipated, no glycemic response to glucagon was noted before glucocorticoid treatment, but a prompt glycemic response to the hormone was obtained after steroid administration.

Plasma amino acid profiles. Quantitative amino acid profiles of seven normal and six ketotic hypoglycemic children before and after the ketogenic diet are shown in Fig. 8; basal levels are shown in the upper panel and the levels after the provocative diet are shown in the lower panel. In the postabsorptive state, the only significant differences between the two groups are the lower plasma alanine levels and elevated leucine levels in the ketotic hypoglycemic children. After the ketogenic diet, the only significant difference is the markedly depressed alanine levels in the ketotic hypoglycemic subjects. There was a tendency for the other gluconeogenic amino acids (e.g., threonine, serine, proline, and glycine) to be depressed. It should be emphasized that the plasma samples of ketotic hypoglycemic children were obtained 8-16 hr after initiating the ketogenic diet (in these children the study had to be stopped because of the appearance of symptomatic hypoglycemia), whereas the plasma samples from normal children were obtained 32-36 $\mathrm{hr}$ after the diet was instituted. In all likelihood, if comparison was made with normal plasma samples drawn $16 \mathrm{hr}$ after beginning the ketogenic diet, the depressed levels of all the glucogenic amino acids seen in the ketotic hypoglycemic children would be significant.

\section{DISCUSSION}

The maintenance of a normal plasma glucose level in the fasted state is dependent upon the ability of the organism to meet the obligatory glucose demands of the central nervous system, formed elements of the blood, and other tissues such as the renal and adrenal medulla (11). It is unlikely that accelerated glucose utilization contributes to the development of hypoglycemia in ketotic hypoglycemic $(\mathrm{K}-\mathrm{H})$ children, since reactive hypoglycemia is not a characteristic feature of this disorder and estimates of the rate of glucose utilization in the postabsorptive state by intravenous glucose tolerance testing have generally been in the normal range (i.e., $2.5-3 \%$ / min.) $(4,16)$. In the hours immediately after carbohydrate deprivation, the demand for glucose is met primarily by hepatic glycogenolysis. A $20-25 \mathrm{~kg}$ child has sufficient glycogen reserves, assuming a hepatic glycogen content of $4-6 \mathrm{~g} / 100 \mathrm{~g}$ and a basal glucose requirement of $2.0-4.0 \mathrm{~g} / \mathrm{hr}(12,13)$, to maintain a normal

\footnotetext{
${ }^{3}$ Karl, I. E., A. S. Pagliara, and D. M. Kipnis. Specific enzymatic fluorometric methods for determination of glutamine and glutamate. Manuscript in preparation.
}

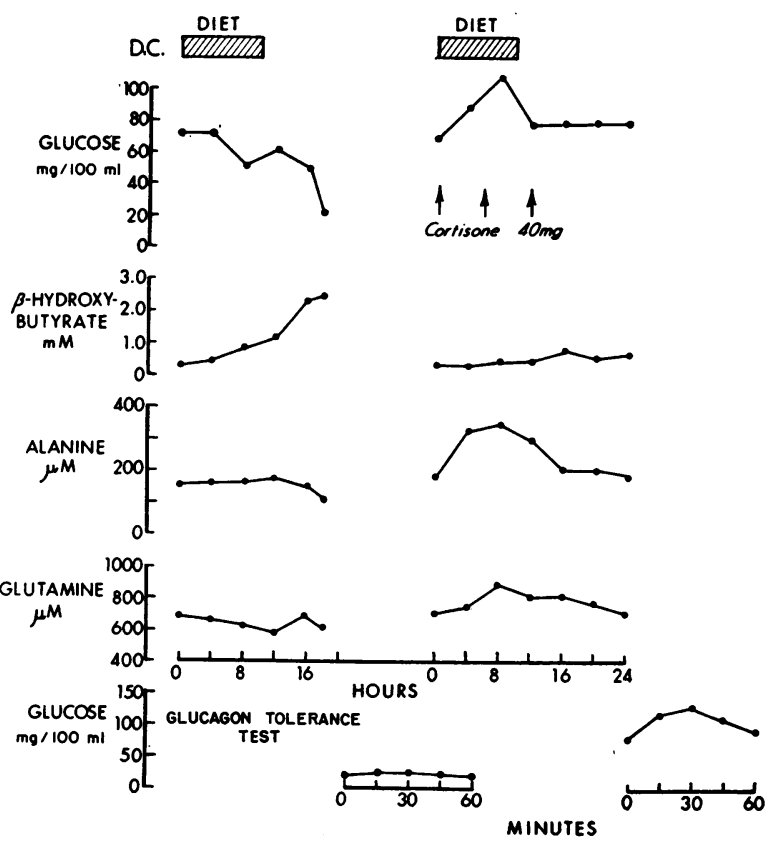

Figure 7 Response to the provocative ketogenic diet with and without cortisone acetate administration. Patient D. C. underwent two challenges with the ketogenic diet. Oral cortisone acetate $40 \mathrm{mg}$ every $6 \mathrm{hr}$ for three doses was administered during the second challenge. The response to intravenous glucagon $0.03 \mathrm{mg} / \mathrm{kg}$ body weight is shown at the bottom of the figure, $18 \mathrm{hr}$ after the first and $24 \mathrm{hr}$ after the second challenge.

blood sugar level during an 8-10 hr fast exclusively by activation of the glycogenolytic mechanism. Recent studies in two children with hepatic fructose-1,6-diphosphatase deficiency support this conclusion, since these individuals did not develop hypoglycemia until after $10-12 \mathrm{hr}$ fasting $(14,15)$. Since hepatic gluconeogenesis begins to increase 4-6 hr after initiating caloric deprivation, hepatic glycogenolysis probably continues to contribute to the maintenance of the blood sugar level for periods

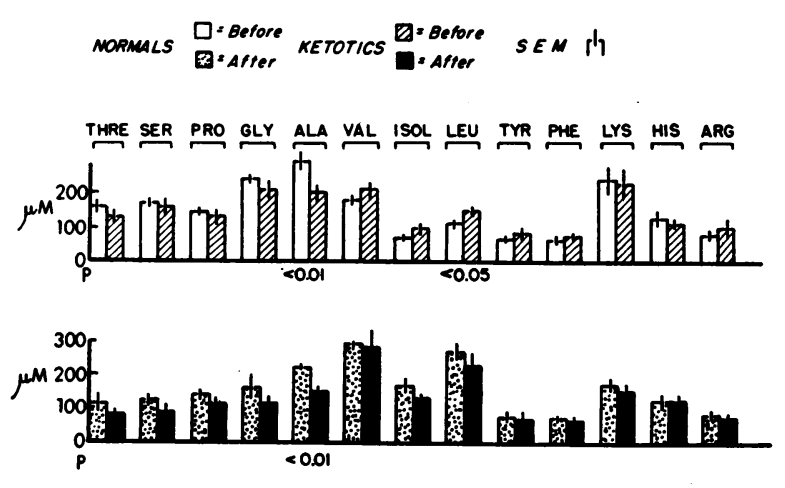

FIGURE 8 Comparison of the plasma amino acid concentrations before and after the ketogenic diet in seven control and six ketotic hypoglycemic children. 
somewhat longer than 8-10 hr. Haultman and Nilsson (17) have recently reported that during starvation the hepatic glycogen level in man progresively falls during the initial $12-14 \mathrm{hr}$ to $\sim 0.5 \mathrm{~g} / 100 \mathrm{~g}$, after which it remains relatively constant. After more prolonged periods of fasting (i.e., 24-36 hr), however, gluconeogenesis becomes the sole source of glucose production. Since ketotic hypoglycemic children tolerate short periods of fasting (i.e., 8-12 hr) and exhibit normal glycemic responses to glucagon under these conditions (Fig. 3), it seems reasonable to conclude that their hepatic glycogen synthetase-phosphorylase system is intact.

The inability of $\mathrm{K}-\mathrm{H}$ children to maintain normal blood glucose levels when fasted or maintained on a carbohydrate deficient diet (i.e., ketogenic diet) for periods of $\sim 24 \mathrm{hr}$ or longer (Table II, Fig. 1) is highly suggestive of a functional defect in hepatic gluconeogenesis. Until recently, attention has been focused primarily on the hormonal adaptations to the fasting state and/or the integrity of the hepatic gluconeogenic enzymic apparatus as the most likely cause(s) of an inadequate gluconeogenic response. The results of our studies as well as those of others $(3,4)$ would appear to exclude hyperinsulinism as an etiologic factor leading to hypoglycemia. Plasma insulin levels of $\mathrm{K}-\mathrm{H}$ children are comparable to those of normal controls in the postabsorptive state, and during fasting they exhibit an appropriate response; namely, falling to less than $5 \mu \mathrm{U} / \mathrm{ml}$ (the maximal sensitivity of the immunoassay used in the present study). Furthermore, their plasma insulin responses to a provocative stimulus (i.e., glucagon) are similar to those of normal children. Of particular interest is the observation that the plasma insulin secretory response to glucagon is completely inhibited in both normal and $\mathrm{K}-\mathrm{H}$ children when their plasma glucose levels fell below $50 \mathrm{mg} / 100 \mathrm{ml}$ (Fig. 3). These results are consistent with previous findings, using in vitro pancreatic islet preparations, that a critical level of glucose (i.e., $50-100 \mathrm{mg} / 100 \mathrm{ml}$ ) is required for either cyclic AMP or activators of the adenyl cyclase system (e.g., glucagon) to stimulate insulin secretion (18). Although plasma glucagon levels were not measured in this study, the presence of a normal glucagon secetory system is suggested by the absence of reactive hypoglycemia (19) and the progressive fall in plasma alanine seen during fasting (20). Furthermore, since K-H children exhibit normal glucocorticoid and growth hormone responses to metyrapone and insulin-induced hypoglycemia (4), respectively, it appears that the usual hormonal adaptations which predispose to an accelerated rate of hepatic gluconeogenesis during fasting are intact.

Our studies also indicate that the gluconeogenic enzymic apparatus of $\mathrm{K}-\mathrm{H}$ children is intact. A characteristic feature of the fasting hypoglycemia associated with the two known hepatic gluconeogenic enzyme deficiencies (i.e. glucose-6-phosphatase [21] and fructose-1,6-diphosphatase $[14,15])$ is the concurrent development of lactic acidosis consequent to the accumulation of gluconeogenic precursors below the level of the enzyme block. Lactic acidosis, however, does not develop in K-H children during fasting. In fact, plasma lactate and pyruvate levels in these patients remained unchanged from basal values even in the presence of symptomatic hypoglycemia (Table II and Fig. 1). Furthermore, K-H children exhibit a rapid rise in plasma glucose during infusions of alanine without any significant change in plasma lactate (Figs. 4-6), whereas a comparable infusion in a patient with fructose-1,6-diphosphatase deficiency produced a decrease in plasma glucose and resulted in a prompt and dramatic increase in plasma lactate (14). Muller, Faloona, and Unger (22) have recently reported that alanine provokes the secretion of endogenous pancreatic glucagon. Since exogenous glucagon does not elicit a glycemic response in the $\mathrm{K}-\mathrm{H}$ child when hypoglycemic, the glycemic response to alanine cannot be attributed to the secretion of endogenous glucagon. The ability of $\mathrm{K}-\mathrm{H}$ children to convert alanine to glucose rapidly is further evidence of the intactness of their gluconeogenic enzymic system.

In recent years, evidence has accumulated from studies in man $(23,24)$ and with the perfused liver $(25,26)$ which indicates that during fasting the availability of gluconeogenic precursor(s) represents a rate-limiting determinant of hepatic gluconeogenesis. Exton and Park noted that a mixture containing physiological levels of lactate, pyruvate, glycerol, and various amino acids, including alanine, did not saturate the gluconeogenic capacity of the perfused rat liver and that under these conditions, alanine accounted for more than $25 \%$ of the glucose produced (26). Felig, Owens, Wahren, and Cahill (23) observed that in fasted man, the arterial alanine level was the primary determinant of hepatic alanine uptake and that when plasma alanine levels were raised by intravenous infusions, a prompt hyperglycemic response occurred (27). In the postabsorptive period (i.e. $12 \mathrm{hr}$ fasting), approximately $15 \%$ of net glucose production by the liver reflects gluconeogenesis, the remainder being derived by glycogenolytic processes. Under these conditions, alanine uptake by the liver, if completely converted to glucose, accounts for less than $6 \%$ of the glucose produced. However, alanine extraction by the liver is markedly increased during fasts of $24-48 \mathrm{hr}$ and may account for $>30 \%$ of net glucose production (23). Therefore, it seems reasonable to anticipate that a marked deficiency in alanine flow to the liver can result in an inadequate rate of gluconeogenesis and the development of hypoglycemia during a $24-48 \mathrm{hr}$ fast. Hypoglycemia is not observed in $\mathrm{K}-\mathrm{H}$ children in the postab- 
sorptive state but typically appears after carbohydrate deprivation for periods of $24 \mathrm{hr}$ or longer. Although studies comparable to those described in adults have not been carried out in children, there is no a priori reason for assuming that the relationships between gluconeogenic precursor availability and hepatic glucose production in children are not similar to those in adults.

On the basis of plasma levels, our studies indicate that the availability of lactate and pyruvate as gluconeogenic precursors in K-H children is comparable to that in normal youngsters. Senior and Loridan (3) have shown that the plasma glycerol levels of $\mathrm{K}-\mathrm{H}$ children are also similar to those of normal children. Furthermore, glycerol infusions produce a prompt glycemic response in $\mathrm{K}-\mathrm{H}$ subjects indicating an intact gluconeogenic system above the level of the triose phosphates (3). In contrast to these gluconeogenic precursors, alanine flow to the liver in $\mathrm{K}-\mathrm{H}$ children is severely limited. Postabsorptive plasma alanine levels in $\mathrm{K}-\mathrm{H}$ children are less than $65 \%$ of normal values and are even lower than those seen in normal children subjected to $44 \mathrm{hr}$ of carbohydrate deprivation. These low postabsorptive levels decrease further (i.e., $25-30 \%$ ) when the $\mathrm{K}-\mathrm{H}$ child is deprived of carbohydrate for an additional $8-16 \mathrm{hr}$, and it is at this time that symptomatic hypoglycemia becomes evident. Under these conditions, the administration of alanine, either as an oral load, intravenous bolus, or sustained intravenous infusion, produces a prompt glycemic response, remission of clinical symptoms of hypoglycemia, and a progressive decline in the blood $\beta$-hydroxybutyrate level. When these children are hypoglycemic, intravenous glucagon does not elicit a detectable glycemic response, although it does produce a modest $(\sim 20 \%)$ fall in the plasma alanine level. This result suggests that glucagon is capable of stimulating the hepatic extraction of alanine $(20,25)$ during hypoglycemia, but that the net increase in alanine uptake is insufficient to produce a measurable increase in glucose production. When the plasma alanine level is raised by a sustained infusion, however, glucagon provokes a prompt rise in plasma glucose (Fig. 6 ) indicating that the supply of this gluconeogenic precursor is the rate-limiting determinant for an appropriate glucagon response.

A deficient supply of other gluconeogenic amino acids may also contribute to the development of hypoglycemia in this disorder. Quantitative amino acid profiles determined on the amino acid analyzer in both normal and $\mathrm{K}-\mathrm{H}$ children before and after carbohydrate deprivation indicated that the only significant difference in gluconeogenic amino acids was represented by a depressed plasma alanine level in $\mathrm{K}-\mathrm{H}$ children. It should be noted, however, that the values shown in Fig. 8 represent plasma levels in K-H children deprived of carbohydrate for $\sim 24 \mathrm{hr}$, whereas the values for normal children were obtained after $44-48 \mathrm{hr}$ of carbohydrate deprivation. It is possible, therefore, that the depressed levels of threonine, serine, and proline noted in $24 \mathrm{hr}$ fasted $\mathrm{K}-\mathrm{H}$ children are significantly lower than those of normal children starved for a comparable period. Marliss, Aoki, Pozefsky, Most, and Cahill (28) have recently demonstrated that glutamine represents another major gluconeogenic precursor in fasting man. Since glutamine cannot be determined with the usual automated amino acid analyzer techniques (28-30), this amino acid was not routinely assayed in the present study. Recently, an enzymatic fluorometric method for determination of glutamate and glutamine has been developed in our laboratory and preliminary studies in four $\mathrm{K}-\mathrm{H}$ patients indicate that their postabsorptive and $24 \mathrm{hr}$ fasted glutamine levels are significantly lower than normal.

Colle and Ulstrom (2) were the first to demonstrate that glucocorticoid administration protects the $\mathrm{K}-\mathrm{H}$ child from developing hypoglycemia when deprived of carbohydrate. Based on this finding, these authors raised the possibility that gluconeogenesis from protein was impaired in this disorder. Although glucocorticoids induced a marked increase in the activity of a number of key gluconeogenic enzymes (i.e., glucose-6-phosphatase, fructose-1,6-diphosphatase, pyruvate carboxylase, and phosphoenolpyruvate carboxykinase [31]), it is unlikely that these changes account for the therapeutic effectiveness of the steroid, since alanine flow to the liver appears to be the dominant rate-limiting factor. Rather it would appear that the effectiveness of these steroids is primarily a consequence of their potent protein catabolic effect. Our studies indicate that cortisone acetate given orally produces a rapid increase in plasma alanine and glutamine which is sustained during carbohydrate deprivation and provides sufficient gluconeogenic precursor to maintain a rate of gluconeogenesis adequate to prevent the development of hypoglycemia. Furthermore, under these conditions glucagon elicits a prompt glycemic response (Fig. 7).

The cause of hypoalaninemia in patients with ketotic hypoglycemia is not apparent from these studies. The major portion of plasma alanine is derived from skeletal muscle where it is released by a carrier-mediated transport system and represents the end product of transamination of pyruvate derived from glycolytic and protein catabolic sources (25). Consequently, a defect in any one of these processes (e.g. transport, protein catabolism, transamination, glycolysis) could result in a decreased availability of alanine and/or other gluconeogenic amino acids for hepatic gluconeogenesis. Although the hypoalaninemia demonstrated in these children could be due to increased gluconeogenesis secondary to increased peripheral glucose utilization, this speculation is less likely since rates of glucose utilization by both intrave- 
nous (4) and oral glucose tolerance testing (2) do not differ from normals. Until additional information on each of these processes in $\mathrm{K}-\mathrm{H}$ children is available, however, further speculation is not warranted. In the original clinical descriptions of this syndrome (2), it was pointed out that these children are frequently below the 50th percentile in both height and weight but generally more retarded in weight than height. Although this has also been our general experience, exceptions have been noted. Nevertheless, this clinical correlation and the observation that even normal children have difficulty in maintaining a normal blood sugar level in prolonged starvation-in contrast to adults-suggest that in the early years of life the balance of available gluconeogenic reserves versus the tissue mass having an obligatory requirement for glucose is at a more precarious balance than in the mature individual. Therefore, any defect compromising the availability of gluconeogenic reserves would be more likely to be clinically apparent early in life. In this context, it would be of interest to determine the ability of adults, who exhibited the ketotic hypoglycemic syndrome during childhood, to maintain their blood sugar level when stressed with a prolonged fast.

It has been suggested that hypoglycemia in the $\mathrm{K}-\mathrm{H}$ syndrome is secondary to the propensity of these children to develop ketonemia (2). Although there is some disagreement in the literature concerning the effectiveness of ketone bodies as insulin secretogogues in man (32-34), the fact that plasma insulin levels in $\mathrm{K}-\mathrm{H}$ children are appropriately decreased during fasting (Ref. 3, Fig. 3) would argue against this hypothesis. Furthermore, $\mathrm{K}-\mathrm{H}$ children respond to infusions of ketone bodies in a manner comparable to that seen in normal youngsters (5). Our finding that the inverse relationship of the plasma glucose versus blood plasma ketone level is identical in K-H children and control subjects (Fig. 2), suggests that ketonemia is a consequence of rather than the cause of hypoglycemia.

\section{ACKNOWLEDGMENTS}

We wish to thank Mr. Thomas Howard and Mr. Larry Buxbaum for their expert technical assistance.

This research was supported by Research Grant No. AM01921-14 and Clinical Research Center Grant No. RR00036, St. Louis Children's Hospital, from the National Institutes of Health.

\section{REFERENCES}

1. Cornblath, M., and R. Schwartz. 1966. Disorders of Carbohydrate Metabolism in Children. W. B. Saunders Company, Philadelphia. 234.

2. Colle, E., and R. H. Ulstrom. 1964. Ketotic hypoglycemia. J. Pediat. 64: 632.
3. Senior, B., and L. Loridan. 1969. Gluconeogenesis and insulin in the ketotic variety of childhood hypoglycemia and in control children. J. Pediat. 74: 529.

4. Grunt, J. A., M. E. McGarry, A. T. McCollum, and J. B. Gould. 1970. Studies of children with ketotic hypoglycemia. Yale J. Biol. Med. 42: 420.

5. Loridan, L., and B. Senior. 1970. Effects of infusions of ketones in children with ketotic hypoglycemia. J. Pediat. 76: 69.

6. Cahill, J. F., Jr., M. G. Herrera, A. P. Morgan, J. S. Soeldner, J. Steinke, P. L. Levy, G. H. Reichard, Jr., and D. M. Kipnis. 1966. Hormonal-fuel interrelationships during fasting. J. Clin. Invest. 45: 1751.

7. Lowry, O. H., J. V. Passonneau, F. X. Hesselberger, and D. W. Schulz. 1964. Effect of ischemia on known substrates and co-factors on the glycolytic pathway in brain. J. Biol. Chem. 239: 18.

8. Huggett, A. St. G., and D. A. Nixon. 1957. Use of glucose oxidase, peroxidase and $O$-dianisidine in determination of blood and urinary glucose. Lancet. 2: 368 .

9. Technicon Autoanalyzer Methodology, Technicon Chromatography Corp., Copyright 1960. Chauncey, New York.

10. Morgan, C. R., and A. Lazarow. 1963. Immunoassay of insulin: two antibody system. Plasma insulin levels of normal, subdiabetic and diabetic rats. Diabetes. 12: 115 .

11. Cahill, G. F., Jr. 1970. Starvation in man. N. Engl. J. Med. 282: 668 .

12. Adam, P. A. J., K. King, and R. Schwartz. 1968. Model for the investigation of intractible hypoglycemia. Insulin glucose relationships during steady-state infusions. Pediatrics. 41: 91 .

13. King, K. C., P. A. J. Adam, G. A. Clemente, and R. Schwartz. 1969. Infants of diabetic mothers: attenuated glucose uptake without hyperinsulinemia during continuous glucose infusions. Pediatrics. 44: 381.

14. Pagliara, A. S., I. E. Karl, J. Keating, B. Brown, and D. M. Kipnis. 1970. Hepatic fructose-1,6-diphosphatase deficiency: a cause of lactic acidosis and hypoglycemia in infancy. J. Lab. Clin. Med. 76: 1020.

15. Baker, L., and A. I. Winegrad. 1970. Fasting hypoglycemia and metabolic acidosis associated with deficiency of hepatic fructose-1,6-diphosphatase activity. Lancet. 2: 13.

16. Bondy, P. K. 1969. Disorders of carbohydrate metabolism. In Duncan's Diseases of Metabolism. P. K. Bondy and L. E. Rosenberg, editors. W. B. Saunders Company, Philadelphia. 6th edition. 223.

17. Haultman, E., and L. H. Nilsson. 1971. Liver glycogen in man. Effects of different diets and muscular exercise. In Muscle metabolism during exercise; proceedings of a Karolinska institute symposium held in Stockholm, Sept. 6-9, 1970. B. Pernow and B. Saltin, editors. Plenum Publishing Corporation, New York. 143.

18. Malaisse, W. J., F. Malaisse-Lagal, and D. Mayhew. 1967. A possible role for the adenylcylase in insulin secretion. J. Clin. Invest. 46: 1724.

19. Levy, L. S., G. Speigel, and S. J. Bleicher. 1970. Glucagon deficient man: model for the role of glucagon in fasting. Presented at the 52nd annual meeting of the Endocrine Society, St. Louis, Missouri. 134.

20. Marliss, E. B., T. T. Aoki, R. H. Unger, J. S. Soeldner, and G. F. Cahill, Jr. 1970. Glucagon levels and metabolic effects in fasting man. J. Clin. Invest. 49: 2256.

21. Huijing, J. F., and J. H. Van De Kamer. 1969. A screening method for liver glycogen storage diseases. Arch. Dis. Childhood. 44: 311.

22. Muller, W. A., G. R. Faloona, and R. H. Unger. 1971. 
Alanine-glucagon relationships in the control of gluconeogenesis. Clin. Res. 19: 480.

23. Felig, P., O. E. Owens, J. Wahren, and G. F. Cahill, Jr. 1969. Amino acid metabolism during prolonged starvation. J. Clin. Invest. 48: 584.

24. Adibi, S. A. 1968. Influence of dietary deprivations on plasma concentrations of free amino acids in man. $J$. Appl. Physiol. 25 : 52.

25. Mallette, L. E., J: H. Exton, and C. R. Park. 1969. Control of gluconeogenesis from amino acids in the perfused rat liver. J. Biol. Chem. 244: 5713.

26. Exton, J. H., and C. R. Park. 1967. Control of gluconeogenesis in liver. I. General features of gluconeogenesis in the perfused livers of rats. J. Biol. Cheim. 242: 2622.

27. Felig, P., E. Marliss, T. Pozefsky, and G. F. Cahill, Jr. 1970. Amino acid metabolism in the regulation of gluconeogenesis in man. Amer. J. Clin. Nutr. 23: 986.

28. Marliss, E. B., T. T. Aoki, T. Pozefsky, A. S. Most, and J. F. Cahill, Jr. 1971. Muscle and splanchnic glutamine and glutamate metabolism in post-absorptive and starved man. J. Clin. Invest. 50: 814.
29. Pagliara, A. S., and A. D. Goodman. 1969. Elevation of plasma glutamate in gout. N. Engl. J. Med. 281: 767.

30. Pagliara, A. S., and A. D. Goodman. 1968. Pitfalls in the determination of plasma glutamate. N. Engl. J. Med. 279: 1402.

31. Weber, G., R. L. Singhal, and S. K. Srivastava. 1965. Action of glucocorticoid as inducer and insulin as suppressor of biosynthesis of hepatic gluconeogenic enzymes. In Advances in Enzyme Regulation. G. Weber, editor. Pergamon Press, Inc., New York. 3: 43.

32. Fajans, S. S., J. C. Floyd, Jr., R. F. Knopf, and S. W. Conn. 1967. Effect of amino acids and proteins on insulin secretion in man. Recent Progr. Hormone Res. 23: 617.

33. Madison, L. L., D. Mebane, R. H. Unger, and A. Lochner. 1964. The hypoglycemic action of ketones. II. Evidence for a stimulatory feedback of ketones on the pancreatic beta cells. J. Clin. Invest. 43: 408.

34. Pi-Sunyer, F. X., R. G. Campbell, and S. A. Haskins. 1970. Experimentally induced hyperketonemia and insulin secretion in the dog. Metab. (Clin. Exp.). 19: 263. 